\title{
NEOLIBERALIZAÇÃO DA INFRAESTRUTURA: MUDANÇAS REGULATÓRIAS E CONFIGURAÇÃO DO SETOR ELÉTRICO BRASILEIRO (1990-2018*
}

\author{
Recebido: 15 de junho de 2018 • Aprovado: 29 de setembro de 2018 \\ https://doi.org/10.22395/seec.v22n50a8 \\ Deborah Werner** $^{* *}$
}

\section{RESUMO}

O artigo tem como objetivo analisar as rodadas de neoliberalização e a configuração do setor elétrico brasileiro, resultante das reformas setoriais das décadas de 1990 e, além da proposta de privatização da Eletrobrás, a partir de 2017. Por meio da análise de dados secundários e documentos referentes ao setor elétrico, submetidos ao referencial teórico acerca dos processos de neoliberalização, verifica-se que as reformas permitiram a atuação de novos agentes setoriais e revelam o vínculo desse setor com a inserção internacional do país, relacionada à exportação de commodities e à financeirização, o que se atesta na análise da cadeia societária das hidrelétricas.

\section{PALAVRAS-CHAVE}

Neoliberalização; infraestrutura; reformas regulatórias; políticas governamentais; energia elétrica Brasil.

\section{CLASSIFICAÇÃO JEL} H54, P1 1, Q48

\section{CONTEÚDO}

Introdução. 1. Rodadas de Neoliberalização pós-1990; 2. A configuração do setor elétrico brasileiro após as reformas; 3. A nova rodada neoliberal: a retomada das privatizações; 4. Conclusões; Bibliografia.

\footnotetext{
A investigação originou-se das pesquisas realizadas no âmbito da tese de doutorado intitulada "Estado, capitais privados e territórios no processo de reconfiguração do setor elétrico brasileiro pós-1990", defendida pela autora no Programa de Pós-Graduação em Planejamento Urbano e Regional, no Instituto de Pesquisa e Planejamento Urbano e Regional (IPPUR), da Universidade Federal do Rio de Janeiro (UFRJ), em 2016. A continuidade das análises, que envolvem o processo de financeirização do setor de infraestrutura e as reformas setoriais pós-2016, têm sido realizadas no grupo de pesquisa "Espaço e Poder", registrado no Conselho Nacional de Desenvolvimento Científico e Tecnológico (CNPQ).

. Economista, Universidade Federal de Uberlândia, Brasil. Mestre em Desenvolvimento Econômico, Universidade Estadual de Campinas, Brasil. Doutora em Planejamento Urbano e Regional, Universidade Federal do Rio de Janeiro, Brasil. Professora do Instituto de Pesquisa e Planejamento Urbano e Regional, Universidade Federal do Rio de Janeiro, Brasil. Pesquisadora do Grupo de Pesquisa registrado no Conselho Nacional de Desenvolvimento Científico e Tecnológico (CNPQ) "Espaço e Poder", e membro do Grupo de Trabalho Clacso "Desarrollo, espacio y capitalismo global" (2016-2019). E-mail: deborahwernerippur@gmail.com
} 


\title{
NEOLIBERALIZACIÓN DE LA INFRAESTRUCTURA: CAMBIOS REGULATORIOS Y CONFIGURACIÓN DEL SECTOR ELÉCTRICO BRASILEÑO (1990-2018)
}

\author{
RESUMEN \\ El artículo tiene como objetivo analizar las rondas de neoliberalización y la configuración del sector \\ eléctrico brasileño, resultante de las reformas sectoriales de las décadas de 1990 y, además de la \\ propuesta de privatización de Eletrobrás, a partir de 2017. Mediante el análisis de datos secundarios \\ y documentos referentes al sector eléctrico, sometidos al referencial teórico sobre los procesos \\ de neoliberalización, se verifica que las reformas han permitido la actuación de nuevos agentes \\ sectoriales y revelan el vínculo de ese sector con la inserción internacional del país, relacionada \\ a la exportación de commodities y a la financierización, lo que se comprueba en el análisis de la \\ composición accionaria de las hidroeléctricas.
}

\section{PALABRAS CLAVE}

Neoliberalización; infraestructura; reformas regulatorias; políticas gubernamentales; energía eléctrica; Brasil.

CLASSIFICACIÓN JEL

$\mathrm{H} 54, \mathrm{P} 11, \mathrm{Q} 48$

\section{CONTENIDO}

Introducción. 1. Rondas de Neoliberalización post-1990; 2. La configuración del sector eléctrico brasileño después de las reformas; 3 . La nueva ronda neoliberal: la recuperación de las privatizaciones; 4. Conclusiones; Bibliografía.

\section{NEOLIBERALIZATION OF INFRASTRUCTURE: REGULATORY CHANGES AND CONFIGURATION OF THE BRAZILIAN ELECTRIC SECTOR (1990-2018)}

\begin{abstract}
The article aims to analyze the rounds of neoliberalization and the configuration of the Brazilian electric sector, resulting from the sectoral reforms of the decades of 1990 and, besides the proposal of privatization of Eletrobrás, from 2017. Through the analysis of secondary data and documents referring to the electrical sector, submitted to the theoretical framework about the processes of neoliberalization, it is verified that the reforms allowed the acting of new sectorial agents and revealed the link of this sector with the international insertion of the country, related to the exportation of commodities and to the financialization, which can be verified in the analysis of the corporate chain of hydroelectric dams.
\end{abstract}

\section{KEYWORDS}

Neoliberalization; infrastructure; regulatory reforms; governmental policies; electrical energy; Brazil.

\section{JEL CLASSIFICATION}

H54, P1 1, Q48

\section{CONTENT}

Introduction. 1. Post-1990 neoliberalization rounds; 2. The configuration of the Brazilian electric sector after the reforms; 3 . The new neoliberal round: the resumption of privatizations; 4 . Conclusions; Bibliography. 


\section{INTRODUÇÃO}

O setor elétrico brasileiro, que ao longo do processo de industrialização (1930-1980) tornou-se monopólio estatal, sobretudo com a constituição das Centrais Elétricas Brasileiras (1962), passou por profundas transformações a partir da década de 1990, em meio às crises fiscal e financeira do Estado na década anterior, que legitimaram a Reforma de Estado sob a influência de ideários neoliberais estabelecidos pelo Consenso de Washington, de 1989.

De acordo com Sauer (2002) e Amaral (2007), as primeiras medidas neolberalizantes da década de 1990 ocorreram ainda no governo Fernando Collor de Mello (1990-1992) com o Programa Nacional de Desestatização (PND), em que as empresas estatais foram impedidas de realizar investimentos para serem saneadas e privatizadas. Além das privatizações, durante o governo Fernando Henrique Cardoso (1994-1998; 1999-2002), as reformas neoliberais no setor elétrico levaram à promoção das concessões de serviços públicos; à substituição do planejamento determinativo pelo planejamento indicativo obediente às leis de mercado; à ênfase no papel regulador do Estado, com a criação da Agência Nacional de Energia Elétrica (Aneel), e à implementação do novo marco regulatório que favorecesse a concorrência entre empresas privadas.

O modelo encontrou seus limites nas fragilidades do marco regulatório e na incompatibilidade das propostas implementadas com a matriz elétrica brasileira, majoritariamente hidrelétrica e dependente de planejamento coordenado de longo prazo, aspecto que ficou evidenciado com o racionamento de energia elétrica, o "apagão" de 2001. As propostas para a superação da crise energética resultaram na reforma setorial de 2004, durante o governo Luis Inácio Lula da Silva (2003-2006; 2007-2010). Nesse período foram questionados os preceitos neoliberais para o setor elétrico, de maneira a resgatar o papel do Estado no planejamento setorial. O então Novo Marco Regulatório de 2004 interrompe o processo de privatização e estabelece novas relações entre a empresa pública e a empresa privada, por meio das parcerias público-privadas (PPP) e das sociedades de propósito específico (SPE). Com o lançamento do Programa de Aceleração do Crescimento (PAC), de 2007, a Eletrobrás, em parceria com empresas nacionais, estrangeiras e fundos de pensão de empresas públicas, promoveu a expansão e a diversificação da matriz elétrica brasileira, que além das hidrelétricas e térmicas, passou a contar com a fonte eólica.

O artigo identifica no setor elétrico brasileiro as rodadas de neoliberalização, entre as décadas de 1990 e 2010, que estabeleceram novas formas de articulação entre o estado e os capitais privados, não no sentido de reduzir a participação do primeiro, mas de, por meio dele, viabilizar a atuação do setor privado ao tornar 
a atividade de geração um espaço para acumulação de capital a grupos que diversificam suas atividades atuando no setor, aspecto que se consolida com o marco regulatório de 2004, por meio das sociedades de propósitos específicos. Em 2016, inaugura-se mais uma rodada com a retomada das privatizações, quando se intensifica a venda de geradoras, aspectos a serem analisados no artigo.

Revela-se que as reformas estão em consonância com a financeirização como padrão sistêmico de riqueza no capitalismo contemporâneo, conforme Braga (1997), e expressam a posição do Brasil na divisão internacional do trabalho na condição de exportador de commodities eletrointensivas. Destaca-se a relevância do papel do Estado nos investimentos e no planejamento setorial no recente período de expansão, o que refuta a dicotomia entre estado e mercado, ao passo que revela as novas articulações entre público e privado no capitalismo contemporâneo. Por fim, revela-se que as propostas de reforma do Governo Michel Temer' (2016-2018) retomam as privatizações setoriais no sentido de promover o aprofundamento do processo de neoliberalização e desnacionalização setorial, que marcaram as reformas do setor elétrico na década de 1990.

A pesquisa, cujo método de análise é o histórico-estrutural, contou com levantamento bibliográfico sobre o setor elétrico brasileiro, documentos de agências governamentais e notícias de imprensa, assim como a constituição de um banco de dados que subsidiou a elaboração de tabelas referentes à participação das empresas na geração de hidroeletricidade no Brasil.

\section{RODADAS DE NEOLIBERALIZAÇÃO PÓS-1990}

As mudanças regulatórias e institucionais do setor elétrico brasileiro, a partir da década de 1990, podem ser compreendidas no âmbito das rodadas de neoliberalização que promovem, nas diversas formações sociais em que são implementadas, o neoliberalismo realmente existente. Brenner, Peck e Theodore (2012) ressaltam a neoliberalização como uma entre as várias tendências regulatórias que emergem a partir da década de 1970, cujas características são a priorização de respostas regulatórias baseadas, orientadas e disciplinadas para e pelo mercado; o esforço em intensificar a comodificação em todos os domínios da vida social, assim como

\footnotetext{
O não reconhecimento do resultado do processo eleitoral, que resultou na reeleição da presidente Dilma Rousseff (Partido dos Trabalhadores, PT), por parte do Partido da Social Democracia Brasileira (PSDB) e seu candidato Aécio Neves, somado ao desgaste na base de apoio do governo, capitaneado por Eduardo Cunha, do Partido do Movimento Democrático do Brasil (PMDB) e intensificado pela ruptura de Dilma Rousseff com o vice-presidente Michel Temer (PMDB), culminaram no impedimento da presidente eleita, sob o argumento de crime fiscal, em 2016.
} 
a mobilização de instrumentos financeiros especulativos para abrir novas arenas para a realização capitalista de lucros.

Theodore, Peck e Brenner (2009) destacam, entre as políticas baseadas nas doutrinas neoliberais, as seguintes: desregulamentação do controle do Estado sobre a indústria; ofensivas contra o trabalho organizado; redução de impostos corporativos, contrações e ou privatização de serviços públicos; desmantelamento nos programas de bem-estar social, ampliação da mobilidade do capital internacional e intensificação da concorrência entre as localidades.

A partir da noção de neoliberalismo realmente existente, os autores buscam romper com a ideologia neoliberal de que as forças de mercado operam de acordo com leis imutáveis, independentemente do lugar onde se realizam. Em contraposição à essa ideia, consideram a inserção contextual dos projetos de reestruturação neoliberal e sua dependência à trajetória herdada do encontro entre as políticas neoliberais com os arcabouços regulatórios precedentes nas distintas formações sociais.

Em contraposição à caricatura neoliberal de redução ou esvaziamento da escala nacional, como resultado necessário e desejável da globalização econômica, Peck (2010) defende uma concepção transescalar e explicitamente politizada do processo de reestruturação regulatória sob o neoliberalismo. Conforme o autor, há momentos criativos e destrutivos no processo de neoliberalização à medida que o processo de desregulação (roll-back) é acompanhado por novas formas de construção da instituição, em conformidade com os determinantes de mercado (roll-out). Por sua vez, o Estado nacional não está em retirada, mas ao contrário, suas formas institucionais e estratégias de regulação estão se reconstituindo e reescalando.

A noção de rodadas de neoliberalização permite compreender as reformas setoriais, cujos determinantes encontram-se no ajuste estrutural a que foi submetida a economia brasileira nos anos $90 \mathrm{com}$ base nas prerrogativas neoliberais do Consenso de Washington (1989), quando legitimam a ideologia de Estado mínimo e alegam a ineficiência de suas instituições nas ações de coordenação e intervenção econômicas. De acordo com Sauer (2002) e Amaral (2007), no setor elétrico tais ideias levaram ao processo de privatização, ao fim do monopólio estatal na geração de energia elétrica, bem como ao marco regulatório com ênfase na concorrência via mercado.

A reforma regulatória foi conduzida de forma gradual e ganhou maior velocidade a partir de 1997, quando as privatizações iniciadas em 1995 — por meio da venda das empresas distribuidoras - já se encontravam em estágio avançado, de modo 
que as mudanças institucionais ocorreram em paralelo com as privatizações. As principais medidas para o setor elétrico envolveram: a regulamentação da Lei Geral de Concessões; o estabelecimento das regras específicas para as concessões do setor elétrico; a criação da Agência Nacional de Energia Elétrica (Aneel); e a criação do Mercado Atacadista de Energia (MAE) e do Operador Nacional do Sistema (ONS).

Com o marco regulatório de 2004, pretendeu-se corrigir aspectos controversos da reforma dos anos de 1990. O planejamento da expansão setorial voltaria a ser de responsabilidade direta de um organismo federal e os leilões — que na década de 1990 se baseavam em concessão onerosa e tinham como vencedor aquele que pagasse maior ágio (valor a mais cobrado em relação ao valor proposto) sobre o preço teto do Megawatt-hora (MWh) — seriam substituídos pela modalidade licitatória referente ao leilão de menor preço, em que receberiam a concessão aqueles que ofertassem as menores tarifas. Essas medidas foram implementadas pelas leis 10.847 e 10.848 , de 15 de março de 2004. É a Lei 10.848 que excluiu a Eletrobrás e suas controladas do PND, o que permitiu a retomada dos investimentos da holding e suas subsidiárias.

Favoreceu a retomada dos investimentos estatais a Lei 11.079, de 30 de dezembro de 2004, referente às normas gerais para licitação e contratação de parceria público-privada no âmbito da administração pública. Tal parceria se realiza a partir da constituição de uma sociedade de propósito específico. As estatais encontraram nas SPEs a possibilidade de retomarem seus investimentos, a partir da constituição de uma empresa privada, sem estarem sob o controle da lei de licitações (Lei 8.666, 1993). Apesar de transferirem recursos técnicos, financeiros, jurídicos, políticos e institucionais para a SPE, o Estado não detém o controle decisório sobre os empreendimentos, o que é impedido pela Lei das Parcerias Público-Privadas (Lei 11.079, 2004).

Por parte do ente privado, a mitigação de riscos em um modelo de constituição de uma SPE ocorre inclusive pela possibilidade de participação do Estado, como atestam Buratini (2004) e Espósito (2012), o que viabiliza o seu envolvimento. Em todos os projetos considerados prioritários pelo Conselho Nacional de Política Energética (CNPE), determina-se a participação de estatais nos consórcios.

As mudanças regulatórias e institucionais no setor elétrico podem ser compreendidas à luz da ideia de neoliberalismo realmente existente, conforme Theodore, Peck e Brenner (2009): ainda que tenha recuperado a participação estatal nos investimentos e no planejamento, o marco regulatório de 2004 preservou mecanismos de mercado trazidos pelas reformas liberais da década de 1990. Apesar de as estatais 
de geração não terem sido privatizadas em sua totalidade e terem retomado os investimentos, a lógica de atuação se tornou privada, no âmbito da concorrência via leilões e do controle dos projetos por parte do parceiro privado em decorrência da constituição de uma SPE, ainda que o capital possa ser majoritariamente estatal.

Embora as reformas se justificassem pela possibilidade de atrair o capital privado, fosse via reestruturação patrimonial como ocorrera na década de 1990, conforme Miranda e Tavares (1999), ou por meio das parcerias público-privadas, a partir de 2004, tais medidas não significaram a redução da atuação estatal nos investimentos do setor elétrico.

Ao contrário, o Estado se mantém nos principais aproveitamentos hidrelétricos, tanto naqueles instalados antes das reformas setoriais quanto nos projetos de expansão, no âmbito do Programa de Aceleração do Crescimento (PAC), a partir de $2007^{2}$. A atuação do Estado se realiza por meio de empresas estatais e de economia mista de geração de energia elétrica, fundos de pensão das empresas estatais (Petros, Previ e Funcef), e como principal financiador dos projetos, através do Banco Nacional de Desenvolvimento Econômico e Social (BNDES), o que fragiliza os argumentos de ausência de recursos do Estado que justifiquem a necessidade de parcerias público-privadas ou ineficiência do ente estatal.

O caráter de capital fixo do tipo infraestrutura justifica a presença do Estado na provisão de infraestrutura, conforme Hirschman (1958) e Harvey (1982), de maneira a elucidar as razões pelas quais historicamente o Estado tem ofertado estradas, portos, plantas energéticas etc.: pelos efeitos que esse tipo de capital acarreta para o processo de acumulação. Nesse sentido, justifica-se a mobilização do fundo público, via crédito de longo prazo ou investimento direto, aspectos que justificaram por parte do Estado tratar a geração de energia e o provimento de infraestrutura como antivalor, de acordo com Oliveira (1988) e Vieira (2007).

Por esse aspecto, não há novidade na intervenção estatal quanto à oferta de infraestrutura, tampouco no uso de fundos públicos. O que há de novo no período atual são as transformações institucionais e regulatórias que, apesar de manterem a importância do Estado como agente setorial, forjam o caráter privado dos projetos, o que os torna espaço para estratégias de acumulação rentista, em consonância com a financeirização como padrão sistêmico de riqueza no capitalismo contemporâneo, conforme Paulani (2016) e Braga (1997). As privatizações e as SPEs promovem a desestatização, a desnacionalização e a financeirização setorial, o que leva à perda

Lançado em janeiro de 2007, pela Lei 11.578, com o objetivo de criar condições macrossetoriais para o crescimento do país no período 2007-2010 (Pêgo e Neto, 2008). Dos investimentos totais previstos para o PAC (2007-2010), R\$ 503 bilhões, 54,5\% seriam destinados aos investimentos de energia elétrica (MDIC, 2007). 
do caráter de antimercadoria ou antivalor atribuído à energia elétrica quando da constituição do setor produtivo estatal, apesar da relevância do Estado, ao viabilizar os investimentos por meio do crédito, participação de estatais ou promoção de mudanças regulatórias.

Considerando o capitalismo sob dominância financeira, Braga (1997, p. 217) afirma que uma vez que as corporações lograram superar as barreiras à entrada, que se impõem às empresas e às firmas individuais, mas não às corporações cuja lógica financeira se apresenta como estratégia de competição, essas corporações passaram a competir umas com as outras em diferentes territórios, de maneira que o espaço da concorrência para esses capitais não é este ou aquele ramo ou estrutura de mercado, mas "um subconjunto do total de ramos/mercados/indústrias que lhes dá escopo para que, na concorrência, suas taxas de retorno se assemelhem de acordo com as magnitudes de capital imobilizados globalmente". Por parte dessas corporações, a territorialidade econômica se amplia seja em termos produtivos, seja em termos financeiros, e isso as torna capazes de definir quadros regulatórios que lhes convenham a partir de um paradigma homogeneizado, proporcionado pelas políticas de globalização, ainda que em seus espaços nacionais de origem tais políticas não tenham sido colocadas em curso.

A acumulação financeira refere-se à modificação dos estados patrimoniais das distintas unidades econômicas e das suas relações de participação no excedente econômico efetivo gerado na economia, logo, conforme Tavares (1978, p. 234), "o capital financeiro não representa, pois, o resultado da produção e acumulação do excedente econômico, e sim da geração e 'acumulação' de direitos de propriedade".

As rodadas de neoliberalização possibilitaram a configuração setorial que se verifica até 2016, com ênfase na formação de SPE, e propiciaram a entrada do setor elétrico na dinâmica da financeirização. Dada a proeminência das estatais nos projetos hidrelétricos oriundos da expansão setorial, o que se verifica com o Programa de Aceleração do Crescimento (PAC), de 2007, ressalta-se a importância delas nesse processo, ainda que as reformas tenham forjado um modelo privado de negócio com as SPE e oferecido espaços de acumulação para capitais privados nacionais e estrangeiros realizarem suas estratégias rentistas, ao se tornarem, sob a tutela estatal, geradores de energia elétrica, como mostrado a seguir.

\section{A CONFIGURAÇÃO DO SETOR ELÉTRICO BRASILEIRO APÓS AS REFORMAS}

A presente seção trata da configuração do setor elétrico após as reformas das décadas de 1990 e 2000, e leva em consideração os projetos já existentes antes das reformas e os aproveitamentos realizados após as alterações no marco regu- 
latório. Verifica-se no setor elétrico que as reformas tornaram-no locus propício para as estratégias competitivas à luz das transformações oriundas do processo de financeirização da riqueza. No âmbito produtivo, destacam-se como geradores os setores primário-exportadores e relacionados à construção civil, aspecto que, juntamente com o caráter de plataforma financeira assumido pelo país a partir das reformas neoliberais, imprime neste setor a posição do Brasil na divisão internacional do trabalho, conforme Paulani (2013).

A análise setorial foi realizada a partir de dados de 185 usinas hidrelétricas (UHEs) em operação registradas no Banco de Informação de Geração (BIG) ${ }^{3}$, responsáveis pela geração de 89.256,04 MW, o que corresponde a 91 \% dos aproveitamentos hidrelétricos e 99,7 \% da capacidade instalada por meio dessa fonte, em 2015. A cadeia societária dos aproveitamentos hidrelétricos permite verificar a configuração do setor elétrico, de modo a revelar a atuação pública e privada nacionais e estrangeiras após o marco regulatório de 2004. Verifica-se, na geração de energia elétrica, a participação de empresas estatais assim como a atuação de multinacionais do setor elétrico, empresas relacionadas à construção civil, mineração e siderurgia, às atividades de serviços financeiros e aos fundos de pensão ${ }^{4}$.

Tanto em termos de número de hidrelétricas como em capacidade instalada, as empresas públicas e de economia mista apresentam expressiva participação nos projetos setoriais, 108 UHEs, o que corresponde a 58,4\% do total analisado, com capacidade instalada de $68.867,58 \mathrm{MW}$ de capacidade instalada ou $77,2 \%$ do total analisado.

Quanto às empresas da União, Furnas Centrais Elétricas está presente no maior número de usinas em operação, 21, ou 19,1 \% da capacidade instalada, seja como detentora da concessão, seja em sociedade. Em quatro deles, a SPE conta com outras estatais: Furnas/CEEE; Furnas/Eletrosul e Furnas/Cemig. Do total, oito projetos ocorreram no âmbito do PAC. Já a Companhia Hidro Elétrica do São Francisco detém a concessão ou participa de projetos que respondem por $16 \%$ da capacidade analisada, seja como detentora da concessão, seja em sociedade. Em dois deles, a sociedade conta com outras estatais (Eletronorte e Eletrosul), ambos do PAC.

As Centrais Elétricas do Norte do Brasil, Eletronorte, detêm a concessão de projetos que respondem por 10,2\% da capacidade instalada, seja como única presente

Os dados analisados no presente artigo são provenientes do Banco de Informação de Geração (BIG) e da Cadeia Societária de Empresas de Geração de Energia Elétrica, ambos disponibilizados pela Agência Nacional de Energia Elétrica (Aneel): Banco de Informação de Geração.

4 O enquadramento das atividades baseia-se no Comissão Nacional de Classificação, do Instituto Brasileiro de Geografia e Estatística (Concla/IBGE), com adaptações. 
na concessão, seja em sociedade com a Chesf. Com relação à Eletrosul Centrais Elétricas S.A., única geradora federal submetida ao processo de desverticalização e privatização de ativos, a empresa retomou as atividades de geração com o marco regulatório de 2004 e participa de três SPEs, com outras estatais (Furnas, Copel e Chesf) e está presente em cinco projetos ou 6,8\% da capacidade instalada analisada. Portanto, verifica-se a atuação das estatais da União em projetos de expansão, relacionados ao PAC, inclusive em sociedade com outras estatais.

Além das geradoras controladas pela União, destacam-se as geradoras estaduais: Companhia Energética de Minas Gerais (Cemig), Companhia Energética do Paraná (Copel), Companhia Estadual de Geração e Transmissão de Energia Elétrica (CEEE), do Rio Grande do Sul, e a Companhia Energética de São Paulo (CESP) $)^{5}$. A Cemig, companhia de capital aberto controlada pelo estado de Minas Gerais, é a empresa estadual com maior presença na capacidade de geração hidrelétrica instalada no país. Além de deter a concessão em projetos que respondem por 13,4 \% da capacidade instalada (incluindo a Light e as SPEs com Furnas, no âmbito do PAC).

Das 30 UHEs em operação oriundas do PAC, que respondem por 14.830,29 MW, 17 projetos contam com a participação de empresas estatais e economia mista e respondem por 12.081,29 MW, ou seja, 81,5\% da capacidade instalada no âmbito do PAC (Tabela 1).

A análise das hidrelétricas no âmbito do PAC revela a importância das empresas estatais e de economia mista na expansão da capacidade instalada setorial, o que contribui para o desempenho do programa governamental e para o cumprimento do planejamento setorial, mesmo em projetos não considerados estruturantes pelo planejamento setorial. Revela ainda que mesmo perante as possibilidades propiciadas à participação das empresas privadas na expansão setorial, o processo se consolida com a atuação de parcerias com as empresas controladas pelo Estado. Quanto às multinacionais, se nos anos noventa as empresas americanas e europeias tiveram participação expressiva nas privatizações e adquiriram as distribuidoras, conforme Rosa (2001), nos anos 2000 além dessas, destaca-se o capital chinês. Conforme a Tabela 2, as multinacionais de energia elétrica estão presentes em 47 hidrelétricas em operação, o que corresponde a 25,4 \% dos projetos hidrelétricos em operação no país, responsáveis por 26.921,1 MW, o que corresponde a 30,2 \% da capacidade instalada total analisada.

Em vias de ser privatizada pelo governo de São Paulo. 
Neoliberalização da infraestrutura: mudanças regulatórias e configuração do setor elétrico brasileiro (1990-2018)

Tabela 1. Participação de Estatais e Empresas de Economia Mista no Programa de Aceleração do Crescimento, 2015

\begin{tabular}{lrrrr}
\hline \multirow{2}{*}{ Empresas Estatais/Mistas no PAC } & \multicolumn{3}{c}{ UHE* $^{*}$} & \multicolumn{2}{c}{ Capacidade Instalada } \\
\cline { 2 - 5 } & n. ${ }^{\circ}$ & $\%$ & MW & \multicolumn{1}{c}{$\%$} \\
\hline Furnas Centrais Elétricas S.A. & 4 & 13,3 & 682,4 & 4,6 \\
\hline Eletrosul Centrais Elétricas S.A. & 2 & 6,7 & 125,0 & 0,8 \\
\hline $\begin{array}{l}\text { Companhia Estadual de Geração e Trans- } \\
\text { missão de Energia Elétrica - CEEE }\end{array}$ & 2 & 6,7 & 230,7 & 1,6 \\
\hline Furnas/Cemig & 2 & 6,7 & $3.708,0$ & 25,0 \\
\hline CELG/CEB & 1 & 3,3 & 96,4 & 0,7 \\
\hline CopelL/Eletrosul & 1 & 3,3 & 361,0 & 2,4 \\
\hline DME Energética & 1 & 3,3 & 191,9 & 1,3 \\
\hline Electronorte/Chesf & 1 & 3,3 & 261,0 & 1,8 \\
\hline Eletrosul/Chesf & 1 & 3,3 & $3.750,0$ & 25,3 \\
\hline Furnas/CEEE & 1 & 3,3 & 855,0 & 5,8 \\
\hline Furnas/Eletrosul & 1 & 3,3 & $1.819,8$ & 12,3 \\
\hline Total Estatais/Mista no PAC & 17 & 56,7 & $12.081,3$ & 81,5 \\
\hline Total PAC & 30 & 100,0 & $14.830,28$ & 100,0 \\
\hline
\end{tabular}

- Trata-se dos projetos classificados como Usinas Hidrelétricas por parte do BIG.

Fonte: elaboração própria a partir do Banco de Informação de Geração (BIG), da Agência Nacional de Energia Elétrica (Aneel).

Tabela 2. Participação das empresas multinacionais nas usinas hidrelétricas em operação, 2015

\begin{tabular}{lrrrr}
\hline & \multicolumn{2}{c}{ UHE* } & \multicolumn{2}{c}{ Capacidade Instalada } \\
\cline { 2 - 5 } & $n .^{\circ}$ & $\%$ & MW & $\%$ \\
\hline GDF Suez & 10 & 5,4 & $11.020,30$ & 12,3 \\
\hline AES Corporationais & 9 & 4,9 & $2.644,30$ & 3 \\
\hline Duke Energy International, Brasil Ltda. & 8 & 4,3 & $2.241,30$ & 2,5 \\
\hline China Three Gorges Brasil Energia Ltda./EDP & 6 & 3,2 & $6.967,90$ & 7,8 \\
\hline Iberdrola & 6 & 3,2 & $2.789,90$ & 3,1 \\
\hline Statkraft Energias Renováveis S.A. & 5 & 2,7 & 559,7 & 0,6 \\
\hline Grupo Enel & 3 & 1,6 & 697,7 & 0,8 \\
\hline Total Multinacional & 47 & 25,4 & $26.921,10$ & 30,2 \\
\hline Total geral & 185 & 100 & $89.256,00$ & 100 \\
\hline
\end{tabular}

- Trata-se dos projetos classificados como Usinas Hidrelétricas por parte do BIG.

Fonte: elaboração própria a partir do Banco de Informação de Geração (BIG), da Agência Nacional de Energia Elétrica (Aneel). 
A multinacional que participa no maior número de usinas hidrelétricas em operação é a GDF Suez, atual Engie. A origem de seu capital é franco-belga e sua atuação no país ocorre através da empresa Tractebel Energia S.A., que iniciou suas atividades no Brasil a partir da aquisição, em 1998, da Gerasul, empresa geradora oriunda da desverticalização da Eletrosul. Quanto ao PAC, a GDF Suez é a empresa com a maior participação entre as multinacionais nas obras concluídas pelo PAC.

A China Three Gorges International S.A. (CTG), de capital chinês, ganhou relevância no setor elétrico brasileiro ao adquirir o controle da EDP Portugal, que atua no país por meio da EDP Energias do Brasil. No PAC, a CTG atua com intermédio da EDP Energias do Brasil S.A. e da CWEI (Brasil) Participações Ltda. A CTG também adquiriu a concessão de duas hidrelétricas, Jupiá e Ilha Solteira, pertencentes à Companhia Energética de São Paulo (CESP), no leilão referente às concessões de energia existentes realizado em novembro de 2015, e passou a ser a primeira empresa estrangeira a assumir sozinha a gestão de uma usina hidrelétrica no país, conforme a Empresa Brasileira de Comunicações (EBC, 2016). Em entrevista ao Repórter Brasil (2016), Charles Tang confirma que a expansão da empresa chinesa para o exterior segue o movimento de busca por espaços de acumulação visa encontrar limites para o crescimento no território chinês. A atuação na Amazônia consolida tal tendência na busca pela redução do preço de energia articulada para a exploração de minérios na região Norte e escoamento da soja, por meio de eclusas articuladas à instalação de UHEs.

A empresa de capital espanhol Iberdrola iniciou suas atividades no país durante as privatizações da década de 1990 e sua atuação como agente setorial se dá por meio da empresa Neoenergia, em que detém 39 \% de seu capital total. A Neoenergia é uma empresa de energia elétrica com capital espanhol e brasileiro, sendo a parte brasileira proveniente do fundo de pensão Caixa de Previdência dos Funcionários do Banco do Brasil (Previ).

A participação das multinacionais em projetos hidrelétricos provenientes do PAC é representativa da relevância desses grupos no recente ciclo de expansão da geração de energia elétrica no país: 11 projetos ou 54,5\% da capacidade instalada oriundas do PAC, com destaque para as empresas GDF Suez e Iberdrola (Tabela 3). Revela-se que as reformas permitiram a abertura do mercado brasileiro para a atuação de multinacionais de energia elétrica nos empreendimentos do ciclo expansionista.

Ainda, o leilão de concessão das hidrelétricas oriundas das empresas estatais que não aceitaram a renovação da concessão proposta pela Lei 12.783, abriu espaço 
Neoliberalização da infraestrutura: mudanças regulatórias e configuração do setor elétrico brasileiro (1990-2018)

para ampliar a atuação das empresas estrangeiras no país, como ocorreu com a China Three Gorges, que se tornou concessionária da UHE Ilha Solteira e UHE Jupiá.

Tabela 3. Participação de multinacionais nas usinas hidrelétrica do Programa de Aceleração do Crescimento, 2015

\begin{tabular}{lcrrrr} 
& Multinacional/PAC & \multicolumn{2}{c}{ UHE $^{*}$} & \multicolumn{2}{c}{ Capacidade instalada } \\
\cline { 2 - 5 } & $n .^{\circ}$ & $\%$ & MW & $\%$ \\
\hline Iberdrola & 4 & 13 & $2.317,2$ & 15,6 \\
\hline GDF Suez & 3 & 10 & $5.080,2$ & 34,3 \\
\hline Statkraft Energias Renováveis S.A. & 3 & 10 & 304,7 & 2,1 \\
\hline China Three Gorges Brasil Energia Ltda./EDP & 1 & 3 & 373,4 & 2,5 \\
\hline Total Multinacional/PAC & 11 & 37 & $8.075,6$ & 54,5 \\
\hline Total geral & 30 & 100 & $14.830,3$ & 100,0 \\
\hline
\end{tabular}

* Trata-se dos projetos classificados como Usinas Hidrelétricas por parte do BIG.

Fonte: elaboração própria a partir do Banco de Informação de Geração (BIG), da Agência Nacional de Energia Elétrica (Aneel).

Conforme a Tabela 4, as empresas relacionadas à construção civil não apenas participam do setor elétrico para a construção dos aproveitamentos, mas diversificaram suas atividades e atuam como agentes geradores setoriais (via SPEs), assim como participam da estrutura acionária de empresas geradoras de energia elétrica, a partir das reformas setoriais, de maneira condizente com o processo de financeirização. As empresas relacionadas à construção civil estão presentes na cadeia societária de 42 usinas hidrelétricas em operação no país, ou seja, 22,7 \% do total de projetos analisados, que respondem por 20.131,3 MW ou 22,6 \% da capacidade instalada.

As principais empresas nessa categoria que atuam como agentes setoriais são: Andrade Gutierrez Concessões S.A.; Camargo Corrêa S.A; Odebrecht S.A., e Queiroz Galvão S.A. A participação da Camargo Corrêa se realizou por meio da geradora CPFL Energia S.A. ${ }^{6}$. A empresa também atua diretamente, via Camargo Corrêa Investimento em Infraestrutura, em mais dois projetos.

A exemplo da Camargo Corrêa, nas hidrelétricas de Serra do Facão e Jirau, e da Andrade Gutierrez, presente na UHE Santo Antônio via Cemig, a participação na cadeia societária do empreendimento favorece a atuação dessas empresas nas obras civis, pois ambas fazem parte do consórcio construtor, que no caso da UHE Santo

6 O grupo Camargo Corrêa detinha 24,4 \% do capital total da CPFL e exercia seu controle, ao lado do fundo de pensão Caixa de Previdência dos Funcionários do Banco do Brasil — Previ (30 \%) e do Bonaire Bonaire Participações/Energia SP FIA (15,1%), formada pelos fundos de pensão Funcesp, Petros, Sistel e Sabesprev (CPFL, 2016). 
Antônio, contou ainda com a Odebrecht como responsável pelo projeto. No que se refere ao PAC, os grupos relacionados à infraestrutura e construção civil estão presentes em 30 \% das UHEs, que respondem por 71,8 \% da capacidade instalada no âmbito do programa federal, de acordo com a Tabela 5. Como estratégia de atuação no PAC, tais grupos se associaram em SPEs.

Tabela 4. Participação de empresas de obras de infraestrutura e serviços de engenharia em usinas hidrelétricas, 2015

\begin{tabular}{|c|c|c|c|c|}
\hline \multirow{2}{*}{ Infraestrutura e Serviços de Engenharia } & \multicolumn{2}{|c|}{ UHE* } & \multicolumn{2}{|c|}{ Capacidade Instalada } \\
\hline & $n .^{\circ}$ & $\%$ & MW & $\%$ \\
\hline Andrade Gutierrez Concessões S.A. & 19 & 10,3 & $6.523,60$ & 7,3 \\
\hline Camargo Corrêa & 13 & 7 & $3.711,70$ & 4,2 \\
\hline Camargo Corrêa Investimento em Infraestrutura S.A. & 2 & 1,1 & $3.962,60$ & 4,4 \\
\hline Queiroz Galvão S.A. & 2 & 1,1 & 181,5 & 0,2 \\
\hline J.Malucelli/CMSA/Planex & 1 & 0,5 & 32 & 0 \\
\hline Odebrecht S.A. & 1 & 0,5 & $1.819,80$ & 2 \\
\hline Orteng/Arcadis Logos & 1 & 0,5 & 83,7 & 0,1 \\
\hline Queiroz Galvão S.A./Construtora Barbosa Mello S.A. & 1 & 0,5 & 121,5 & 0,1 \\
\hline Serveng-Civilsan/CEM Engenharia & 1 & 0,5 & 127 & 0,1 \\
\hline Odebrecht S.A./Andrade Gutierrez Concessões S.A & 1 & 0,5 & $3.568,00$ & 4 \\
\hline Total Infraestrutura e Serviços de Engenharia & 42 & 22,7 & $20.131,30$ & 22,6 \\
\hline Total Geral & 185 & 100 & $89.256,00$ & 100 \\
\hline
\end{tabular}

* Trata-se dos projetos classificados como Usinas Hidrelétricas por parte do BIG.

Fonte: elaboração própria a partir do Banco de Informação de Geração (BIG), da Agência Nacional de Energia Elétrica (Aneel).

Apesar de estar presente em apenas dois projetos, a Odebrecht é a que participa de projetos com maior capacidade instalada por meio do programa federal. A empresa é uma holding de capital nacional com atuação no setor de construção civil, tendo diversificado suas atividades para concessões públicas, química e petroquímica. No PAC, o grupo está presente em projetos que respondem por $36 \%$ do total adicionado pelo programa federal. Nesse sentido, ainda que sua participação ocorra em apenas dois projetos, se considerarmos as usinas hidrelétricas em operação, a empresa se configura como a principal construtora presente no setor elétrico quando se analisa a capacidade instalada. 
Neoliberalização da infraestrutura: mudanças regulatórias e configuração do setor elétrico brasileiro (1990-2018)

Tabela 5. Participação de empresas de obras de infraestrutura e serviços de engenharia em usinas hidrelétricas no PAC, 2015

\begin{tabular}{lrrrr}
\hline \multirow{2}{*}{ Infraestrutura e Serviços de Engenharia - PAC } & \multicolumn{2}{c}{ UHE* $^{*}$} & \multicolumn{2}{c}{ Capacidade Instalada } \\
\cline { 2 - 5 } & $n \cdot{ }^{\circ}$ & $\%$ & MW & $\%$ \\
\hline Andrade Gutierrez Concessões S.A. & 1 & 3,3 & 140 & 0,9 \\
\hline Camargo Corrêa & 3 & 10 & $1.085,7$ & 7,3 \\
\hline Camargo Correa Investimento em Infraestrutura S.A. & 2 & 6,7 & $3.962,6$ & 26,7 \\
\hline Odebrecht S.A. & 1 & 3,3 & $1.819,8$ & 12,3 \\
\hline Orteng/Arcadis Logos & 1 & 3,3 & 83,7 & 0,6 \\
\hline Odebrecht S.A./Andrade Gutierrez Concessões S.A. & 1 & 3,3 & $3.568,0$ & 24,0 \\
\hline Total Infraestrutura e Serviços de Engenharia & 9 & 30 & $10.659,70$ & 71,8 \\
\hline Total PAC & 30 & 100 & $14.840,30$ & 100 \\
\hline
\end{tabular}

- Trata-se dos projetos classificados como Usinas Hidrelétricas por parte do BIG.

Fonte: elaboração própria a partir do Banco de Informação de Geração (BIG), da Agência Nacional de Energia Elétrica (Aneel).

A construção civil pode ser compreendida como um dos setores que estruturam o capitalismo brasileiro e se constituiu como tal a partir das demandas por obras públicas do Estado, o que resultou na consolidação de grandes grupos econômicos e multinacionais brasileiras. Se, por um lado, estão imbricadas com a instalação de infraestrutura por serem as fazedoras das obras, por outro, a financeirização permite a participação desse ramo na própria geração elétrica, por meio da diversificação de seus portifólios, seja ao adquirir participação em empresas de economia mista, seja ao participar de SPE.

As empresas de mineração e siderurgia estão presentes em 39 UHEs em operação, o que corresponde a 21 \% dos projetos analisados que, por sua vez, respondem por 8.590,9 MW ou 9,6 \% da capacidade instalada em análise (Tabela 6). Uma vez que parte da participação dessas empresas ocorre por meio do regime de autoprodução, ressalta-se que elas buscam suprir as necessidades de fornecimento de energia elétrica em decorrência do fato de atuarem em atividades eletrointensivas.

Quanto ao PAC, a presença de empresas do ramo de siderurgia e mineração são identificadas em seis projetos, que respondem por 1.739,47 MW ou 11,7 \% da capacidade instalada adicionada pelo programa governamental, todos nas regiões Norte e Centro-Oeste. Destaca-se, no âmbito do PAC, a Alcoa, presente em dois projetos que respondem por $8,7 \%$ do total adicionado pelo programa federal. 
Tabela 6. Participação das empresas de mineração e siderurgia nas usinas hidrelétricas em operação, 2015

\begin{tabular}{|c|c|c|c|c|}
\hline \multirow[t]{2}{*}{ Mineração } & \multicolumn{2}{|c|}{$\mathrm{UHE}^{*}$} & \multicolumn{2}{|c|}{$\begin{array}{l}\text { Capacidade } \\
\text { Instalada }\end{array}$} \\
\hline & $n .^{\circ}$ & $\%$ & MW & $\%$ \\
\hline Votorantim S.A. & 20 & 10,8 & 2012,8 & 2,3 \\
\hline Vale S.A. & 5 & 2,7 & 972 & 1,1 \\
\hline Gerdau S.A. & 3 & 1,6 & 280 & 0,3 \\
\hline Mineração Santa Elina Indústria e Comércio S.A. & 2 & 1,1 & 121,6 & 0,1 \\
\hline Alcoa Alumínio S.A. & 1 & 0,5 & 212,6 & 0,2 \\
\hline $\begin{array}{l}\text { Alcoa Alumínio S.A./Votorantim S.A./InterCement } \\
\text { Brasil }\end{array}$ & 1 & 0,5 & 690 & 0,8 \\
\hline ArcelorMittal/Samarco & 1 & 0,5 & 140 & 0,2 \\
\hline $\begin{array}{l}\text { Companhia Siderúrgica Nacional/Companhia de } \\
\text { Cimento Itambé }\end{array}$ & 1 & 0,5 & $1.450,0$ & 1,6 \\
\hline $\begin{array}{l}\text { Companhia Siderúrgica Nacional/Votorantim S.A./Anglo- } \\
\text { GoldAshanti Córrego do Sítio Mineração }\end{array}$ & 1 & 0,5 & 210 & 0,2 \\
\hline Samarco (Vale S.A./BHP Billiton Brasil Ltda.) & 1 & 0,5 & 25 & 0 \\
\hline Vale S.A./Alcoa Alumínio S.A./InterCement Brasil & 1 & 0,5 & $1.087,0$ & 1,2 \\
\hline Vale S.A./Votorantim S.A. & 1 & 0,5 & 240 & 0,3 \\
\hline $\begin{array}{l}\text { Votorantim S.A./Alcoa Alumínio S.A/Vale S.A./ } \\
\text { InterCement Brasil }\end{array}$ & 1 & 0,5 & 1140 & 1,3 \\
\hline Total Mineração & 39 & 21,1 & $8.580,9$ & 9,6 \\
\hline Total geral & 185 & 100 & $89.256,0$ & 100 \\
\hline
\end{tabular}

"Trata-se dos projetos classificados como Usinas Hidrelétricas por parte do BIG.

Fonte: elaboração própria a partir do Banco de Informação de Geração (BIG), da Agência Nacional de Energia Elétrica (Aneel).

A relação entre energia elétrica, mineração e siderurgia explica-se, de acordo com Cardoso et al. (2011), pela dependência das últimas em relação à expansão energética, especificamente as hidrelétricas, em termos de competitividade e viabilidade dos investimentos. O fato de o Brasil participar da indústria global da atividade de mineração e siderurgia justifica a necessidade de o planejamento setorial contemplar o atendimento a essa demanda e à busca pela redução de seu custo com o intuito de tornar o país competitivo, o que expressa o vínculo entre mineração e energia elétrica e as consequências da especialização em commodities eletrointensivas para o planejamento setorial. 
Ressalta-se, de acordo com a Empresa de Pesquisa Energética (EPE, 2014), que a siderurgia é o setor que responde pela maior participação no consumo de energia industrial do país, apesar da tendência de queda, de maneira que a competitividade do setor está vinculada ao planejamento setorial.

Os fundos de pensão de empresas públicas, por sua vez, estão presentes no setor elétrico tanto na composição acionária de empresas de energia elétrica como nas SPEs. No total, estão presentes em 21 UHEs em operação no país, responsáveis por 6.785,6 MW ou 7,7 \% da capacidade instalada. Desses empreendimentos, oito pertencem ao PAC e respondem por 3.476,96 MW, ou seja, 23,4 \% da capacidade instalada pelo programa.

O principal fundo de pensão é a Caixa de Previdência dos Funcionários do Banco do Brasil (Previ), presente na CPFL e na Neoenergia. Nesta última, detém 49,01 \% do capital total da empresa, em parceria com a espanhola Iberdrola (39\%) e com o Banco do Brasil Investimentos (11,99\%). Através da Neoenergia (Iberdrola), o fundo de pensão participa de seis empreendimentos hidrelétricos que respondem por 2.789,9 MW, dos quais quatro estão inseridos no Programa de Aceleração de Crescimento (PAC). Todas as UHEs em operação inseridas no PAC em que se identificam fundos de pensão, contam com o Previ, seja pela empresa CPFL, seja pela Neoenergia. No total, o Previ está presente em 19 empreendimentos do PAC, que respondem por 6.501,6 MW ou 95,8 \% da capacidade instalada oriunda de projetos em que se identificam os fundos de pensão.

Conforme Jardim (2009), a partir do governo Lula (2003-2006 e 2007-2010), os fundos de pensão de empresas públicas foram colocados à serviço dos investimentos produtivos e direcionados para obras de infraestrutura e se configuraram em uma fonte de recursos importante para viabilizar atividades geradoras de renda e emprego, a exemplo do setor elétrico.

A Tabela 7 mostra a atuação de empresas relacionadas às atividades de serviços financeiros. A presença dessas empresas ocorre em 28 empreendimentos ou 15,1 $\%$ do total analisado. Tais projetos respondem por 11.025,74 MW de capacidade instalada, o que corresponde a 12,4 \%. Ressalte-se a origem dos grupos controladores das atividades de serviços financeiros, com destaque para a construção civil, mineração e siderurgia, além da participação do Estado, que atua através do banco público Banco do Brasil, que investe no setor através do BB Banco de Investimentos S.A.; do BNDES — por meio da participação do Bndespar na formação de empresas 
concessionárias no setor elétrico - e do Fundo de Investimento do Fundo de Garantia por Tempo de Serviço ${ }^{7}$ (FI-FGTS).

Tabela 7. Participação de empresas de atividades de serviços financeiros nas UHE em operação, 2015

\begin{tabular}{lcrrr}
\hline \multirow{2}{*}{ Atividades de Serviços Financeiros } & UHE* & & \multicolumn{2}{c}{ Capacidade instalada } \\
\cline { 2 - 5 } & $n \cdot{ }^{\circ}$ & $\%$ & MW & $\%$ \\
\hline Bndespar & 9 & 4,9 & 2644,3 & 3 \\
\hline BB Banco de Investimentos S.A. & 6 & 3,2 & 2789,9 & 3,1 \\
\hline Brookfield Renewable Energy Partners L.P. & 4 & 2,2 & 338,4 & 0,4 \\
\hline Triunfo Participações e Investimentos & 3 & 1,6 & 1115,4 & 1,2 \\
\hline Alupar Investimento S.A./FI-FGTS & 2 & 1,1 & 119,4 & 0,1 \\
\hline Paineira Participações & 2 & 1,1 & 240,3 & 0,3 \\
\hline Bull Finance Ativos Imobiliários Ltda. & 1 & 0,5 & 210 & 0,2 \\
\hline SAAG Investimentos S.A. (Andrade Gutierrez) & 1 & 0,5 & 3568 & 4 \\
e Caixa FIP Amazônia Energia (Odebrecht & & & & 12,4 \\
Energia S.A. e FI-FGTS) & 28 & 15,1 & $11.025,7$ & 100 \\
\hline Total Atividades Serviços Financeiros & 185 & 100 & $89.256,0$ & \\
\hline Total UHE & & & & 4 \\
\hline
\end{tabular}

- Trata-se dos projetos classificados como Usinas Hidrelétricas por parte do Banco de Informação de Geração.

Fonte: elaboração própria a partir do Banco de Informação de Geração (BIG), da Agência Nacional de Energia Elétrica (Aneel).

O BB Banco de Investimentos S.A. é controlado pelo banco público Banco do Brasil e especializado em mercado de capitais doméstico. Sua participação no setor elétrico se realiza por meio do controle da empresa Neoenergia, juntamente com o fundo de pensão, Previ. Já a empresa SAAG Investimentos S.A. tem como sócia o Grupo Andrade Gutierrez e um fundo de investimentos em participações da Cemig Geração e Transmissão S.A. (que tem como maior sócio privado o Grupo Andrade Gutierrez). Tal participação ocorre na UHE Santo Antônio em sociedade com o Caixa Fundo de Investimento em Participação Amazônia Energia, controlado pelo Fundo de Investimento do FGTS em sociedade com a Odebrecht Energia, criado especialmente para investir nesse empreendimento.

7 O Fundo de Garantia por Tempo de Serviço (FGTS) é uma poupança compulsória do trabalhador empregado, criado em 1964, em substituição à estabilidade do emprego. O trabalhador pode sacá-lo ao ser demitido ou ainda quando da aquisição ou construção de imóvel ou em casos excepcionais, como determinadas doenças. 
Com relação ao FI-FGTS, trata-se do Fundo de Investimento do Fundo de Garantia por Tempo de Serviço, além de estar presente na UHE Santo Antônio, está também na UHE São José e na UHE Foz do Rio Claro, ambas em sociedade com a Alupar Investimentos S.A., empresa especializada no controle de companhias relacionadas ao setor de energia.

O Bndespar é controlado pelo banco público BNDES e, ainda que participe da estrutura societária de várias empresas que atuam no setor elétrico, incluindo as do grupo Eletrobrás, Vale S.A. e relacionadas às atividades de serviços financeiros ${ }^{8}$, aqui foi considerada sua participação na formação de empresa privada de energia elétrica, qual seja, a AES Tietê em associação com a AES Corporation, em que detém 14,6 \% das ações ordinárias da empresa.

A Brookfield Renewable Energy é subsidiária da holding canadense Brookfield Asset Management Inc. e sua atuação no Brasil remonta à Light and Power Company, no final do século XIX. Já a empresa Triunfo detém três empreendimentos, sendo dois deles contemplados pelo PAC e um referente à concessão da UHE Três Irmãos, antes pertencente à CESP, e atualmente à SPE formada pela Triunfo $(50,1$ \%) e Furnas Centrais Elétricas S.A. (49,9\%).

Em termos de capacidade instalada, as atividades de serviço financeiro estão presentes em projetos do PAC que respondem por 6.283,15 MW (42 \% da capacidade instalada pelo programa). Os principais são o Previ e o FI-FGTS, ambos relacionados ao governo federal.

O que se verifica é que predominam nessa categoria as instituições de atividades de serviços financeiros relacionadas às estatais e ao FGTS, de maneira a serem colocados em função da expansão setorial, assim como os fundos de pensão. Ainda, articularam-se com empresas de participação controladas pelos grupos relacionados à construção civil. As atividades de serviços financeiros não apenas encontram nos projetos de capital fixo frentes para diversificarem seus portfólios, como contam com os fundos públicos, por meio dos fundos de pensão das empresas de serviços financeiros relacionadas às empresas e fundos públicos, como FGTS, Bndespar e BB.

Quanto às hidrelétricas em construção9, das dez UHEs em construção, responsáveis por 13.356,24 MW, as estatais e empresas de economia mista estão

\footnotetext{
O Bndespar participa ainda da empresa Triunfo Participações S.A., com 14,8 \% do capital total da empresa.

$9 \quad$ Até a data de 18 de fevereiro de 2016.
} 
presentes em cinco UHEs, responsáveis por 12.983,3 MW ou 96,5\% da capacidade instalada total por esses projetos. A UHE Belo Monte, com 11.233,1 MW, o principal projeto em termos de capacidade instalada em construção, sob responsabilidade do consórcio Norte Energia e no âmbito do PAC, tem em sua estrutura societária três empresas controladas pela Administração Pública Federal: a Eletrobrás, a Chesf e a Eletronorte.

Dada a capacidade instalada da UHE Belo Monte, o empreendimento é representativo do modelo adotado para a expansão setorial após o marco regulatório de 2004. Além da presença das estatais, que detêm a maior parcela do capital apesar do impedimento de controlar a SPE, estão presentes a Cemig e a Vale, que juntas formam a Aliança Energia; a Iberdrola, via Neoenergia, o que consolida também a participação do fundo de pensão Previ e da BB Investimentos; e a empresa Siderúrgica do Norte do Brasil. Além do Previ, outros dois fundos de pensão participam da Norte Energia: Fundação Petrobrás de Seguridade Social (Petrus); e Fundação dos Economiários Federais (Funcef). Ainda, tanto a Siderurgia Norte do Brasil como a Vale participam de Belo Monte no papel de autoprodutoras, dado o caráter eletrointensivo de suas atividades.

A presença de empresas relacionadas a obras de infraestrutura e serviços de engenharia na cadeia societária das hidrelétricas em construção ocorre apenas na UHE Belo Monte, que devido à participação societária da empresa Cemig, via Aliança Energia e via Amazônia Energia (Cemig e Light), tem a Andrade Gutierrez na cadeia societária. Outra empresa do consórcio Norte Energia é a J. Malucelli.

Ainda que estejam presentes em apenas um consórcio, trata-se da UHE Belo Monte, relevante pelo histórico, capacidade instalada e recursos políticos, econômicos e institucionais mobilizados. Quando se verifica o consórcio construtor do empreendimento, identificam-se as principais empresas do ramo, o que é destacado pelo sítio eletrônico do projeto.

O que se verifica nas hidrelétricas em construção é o protagonismo do Estado e das multinacionais na viabilização de investimentos relacionados à expansão setorial. Os principais grupos relacionados à construção civil, ainda que tenham menor destaque na cadeia societária, atuam na instalação da hidrelétrica e são beneficiados pela política setorial. Com relação às empresas relacionadas aos serviços financeiros, destacam-se as empresas controladas pela administração pública articuladas às políticas setoriais.

A próxima seção apresenta a mais recente rodada de neoliberalização, com as mudanças na política do setor elétrico, no governo de Michel Temer (2016-2018). 


\section{A NOVA RODADA NEOLIBERAL E A RETOMADA DAS PRIVATIZAÇÕES}

Conforme Fernández (2016), a América Latina apresenta, nas duas primeiras décadas do século XXI, um duplo movimento: o período neoliberal nos anos de 1990 (primeiro movimento) e a retomada de políticas desenvolvimentistas (segundo movimento), em resposta ao primeiro. A partir de governos progressistas, o projeto neoliberal foi mais ou menos confrontado, de acordo com o país, concomitantemente ao crescimento econômico propiciado pela demanda chinesa por commodities. Tal estratégia permitiu políticas públicas de transferência de renda, investimentos em infraestrutura econômica e social e um reposicionamento geopolítico. No entanto, a debilidade estaria na manutenção do padrão de acumulação predominante no período neoliberal, relacionado à especialização em produtos primários e à inserção financeira. Com a crise financeira internacional de 2008, intensificam-se os questionamentos quanto ao papel do Estado, de maneira a recrudescer na região a empreitada neoliberal, a retomada de políticas de austeridade fiscal e a retirada de direitos trabalhistas acompanhadas de propostas em favor da privatização de ativos públicos, o que reafirma o papel subalterno e periférico da América Latina diante da nova ordem global que emerge com as transformações na economia chinesa.

Após a rodada de neoliberalização da década de 1990, com o governo FHC, em que são implementadas as políticas relacionadas ao Consenso de Washington (1989), os governos Lula e Dilma (2003-2015) primaram por políticas no campo progressista, porém, de acordo com Brandão (2017) mantiveram a macroeconomia conservadora, promoveram reformas da previdência que privilegiaram o mercado financeiro, apostaram em alianças com grupos conservadores relacionados ao rentismo e à especialização em commodities e eximiram-se do enfrentamento da questão urbana e regional. Para o setor elétrico, a despeito da retomada dos investimentos estatais, estes ocorreram em parcerias público-privadas, por meio das SPEs, o que forjou o caráter privado de investimentos públicos. Ainda, permitiu o processo de desnacionalização setorial, com a participação de multinacionais nos consórcios.

Atualmente, de acordo com Brandão (2017), a nova rodada de neoliberalização é inaugurada pelo Governo Temer (2016), que retoma as políticas neoliberais da década de 1990, com profundas consequências ao padrão regulatório vinculado à terra, ao capital e ao trabalho em claro desmonte dos compromissos de classe predominantes no capitalismo fordista, de maneira que o golpe de 2016 reinaugura os anseios da agenda global neolibralizante.

É nesse contexto que se inserem as medidas recentes anunciadas pelo governo no âmbito do setor elétrico brasileiro. A despeito do ciclo expansionista vinculado à ação estatal e ao marco regulatório de 2004, o atual governo justifica a retoma- 
da das privatizações pela suposta ineficiência da ação estatal e pela queda das receitas das empresas estatais, consequência já apontadas por aqueles que foram contrários à Medida Provisória 579, transformada na Lei 12.783, de 2013, quando de sua aprovação.

A Lei 12.783 teve como objetivo promover a queda das tarifas por meio da renovação de concessões que venceriam em 2015 e 2017, uma única vez por 30 anos, conforme permitido pela Lei 9.074, de 1995. Não havendo ativos a serem amortizados, a tarifa dos novos contratos de concessão seriam fixadas apenas pelo custo de serviço, o que corresponde aos custos de operação e manutenção. A medida acarretou o sacrifício econômico-financeiro das empresas públicas e ocorreu sem diálogo com os diversos agentes setoriais, por atender às demandas corporativas, com destaque para a Federação de Indústrias do Estado de São Paulo (Fiesp), o que implicou em sua pouca efetividade para a redução tarifária pretendida.

De acordo com Werner (2016), a consequência da medida foi a intensificação dos conflitos intrasetoriais, sobretudo com a recusa de aceite da medida por parte de Cemig, Copel e Cesp, ambas controladas por empresas estaduais, cujos governos eram de oposição ao governo federal sob o comando de Dilma Rousseff. O que se atesta é que medidas anteriormente estabelecidas ocasionaram a justificativa para as ações neoliberalizantes do Governo Temer e contribuiram para legitimar as condições materiais e discursivas para a venda das empresas estatais.

Em junho de 2017, o Ministério de Minas e Energia submeteu à consulta pública a Nota Técnica 5/2017/Aereg/SE, do Ministério de Minas e Energia (2017), intitulado "Proposta de aprimoramento do marco legal do setor elétrico". Transformações tecnológicas e ambientais justificariam mudanças regulatórias e institucionais capazes de promover mecanismos de mercado no setor elétrico, mais eficazes na promoção de informações adequadas ao planejamento setorial, realizado pelos agentes. Como propostas destacam: i) incentivos à eficiência nas decisões empresariais de agentes individuais como vetor de modicidade tarifária, segurança de suprimento e sustentabilidade socioambiental; ii) sinalização econômica como vetor de alinhamento entre interesses individuais e sistêmicos; iii) alocação adequada de riscos para permitir sua gestão individual, com responsabilidades bem definidas; iv) remoção de barreiras participação de agentes no mercado, e v) respeito aos contratos vigentes e observância dos requisitos formais e dos papéis de cada instituição.

Em linhas gerais, as propostas viriam a enfatizar a necessidade de mudanças regulatórias capazes de ampliar a participação de agentes privados na geração 
elétrica, atraídos pela confiabilidade do marco regulatório e orientados pela alocação eficiente dos mecanismos de mercado. Caberia ao Estado seu papel regulador.

À apresentação da nota técnica seguiu-se a empreitada governamental no sentido de privatizar a empresa estatal Eletrobras. No âmbito das alterações regulatórias, o governo editou a Medida Provisória 814/2017, que retira entraves da venda de distribuidoras da Eletrobras e revoga o artigo 31 da Lei 10.848, de 2004, que excluía a Eletrobras e suas controladas do PND. A MP 814 foi alvo de liminar para suspender a inclusão da Eletrobrás e suas subsidiárias no PND, derrubada pelo Ministro do Supremo Tribunal Federal, Alexandre de Moraes, em atendimento à Câmara dos Deputados e a Advocacia Geral da União, conforme noticiado pela EBC (2018). A privatização da Eletrobrás tem sido, desde então, pauta na Câmara dos Deputados pela aprovação do Projeto de Lei 9.463/18.

Além dos trâmites regulatórios para a privatização da Eletrobrás, o governo tem promovido campanhas publicitárias que atribuem os elevados preços da energia elétrica ao seu caráter estatal, assim como campanhas difamatórias contra funcionários da empresa, contrapostas por inúmeras manifestações e debates promovidos pelos sindicatos e movimentos sociais, conforme Nunes (2017) e Federação Nacional dos Urbanitários (2018). Em fevereiro de 2018, o Senador Hélio José (Pros-DF) protocolou um pedido de criação de uma Comissão Parlamentar de Inquérito para apurar a privatização da Eletrobrás, com a justificativa de investigar possíveis favorecimentos à empresários a partir do acesso à informação privilegiada e irregularidades de agentes públicos nos atos relativos à privatização da Eletrobrás em detrimento dos interesses na União, conforme Murakawa (2018).

A mais recente rodada de neoliberalização propõe retomar as privatizações e a redução do papel do Estado no planejamento, nos investimentos e na coordenação centralizada do setor elétrico. A tendência de desnacionalização, já identificada quando da análise da reconfiguração setorial após o marco regulatório de 2004, deve se intensificar visto o crescente interesse das empresas estatais chinesas na aquisição de hidrelétricas já instaladas.

Em 2017, os chineses ampliaram sua participação no setor elétrico brasileiro, por meio da empresa State Grid Corporation, que se tornou acionista controladora da empresa CPFL Energia S.A., ao adquirir a participação da Camargo Corrêa e dos fundos de pensão Previ, Fundação Cesp, Sabesprev, Sistel e Petros. Conforme dados da Aneel (2017) e reportagem do Estado de São Paulo (2017), a empresa State Power Investment Overseas (SPIC) propôs adquirir a participação que a Cemig detém na UHE Santo Antônio, o que ainda não se confirmou na composição acionária da SPE. 
O mesmo grupo, SPIC, por meio da Pacific Hydro, adquiriu a UHE São Simão, operada pela Cemig, na estratégia de retomada das privatizações, por parte do governo federal e estadual (Minas Gerais). A empresa Pacific Hydro também participa de investimentos eólicos no Nordeste do país.

Segundo Federação Nacional dos Urbanitários (2018b) emergem também como grupos de interesses em prol das privatizações os fundos de pensão americanos e europeus, já detentores de ações da estatal, como os relacionados às empresas ATET, General Eletric, IBM, Boeing, British Airways, Ford, Caterpillar, entre outras, além de fundos ligados a diversos países e fundos de investimentos de bancos internacionais como JP Morgan, Goldman Sachs, HSBC, BNP Paribas. A busca por maior rentabilidade dos diversos fundos financeiros leva a pressões internacionais pelas privatizações.

A crescente privatização e desnacionalização suscitam questões quanto à segurança energética do país e o seu controle na condição de insumo estratégico para a competitividade da economia. A transferência de seu parque gerador a empresas privadas nacionais e estrangeiras e as alegações, por parte do governo, quanto ao esgotamento de um modelo de operação baseado na complementaridade e coordenação sistêmica, a ser substituído por mecanismos de planejamento e coordenação baseados em uma estrutura de mercado concorrencial, em que as expectativas de rentabilidade garantiriam o provimento eficiente de energia elétrica, delegam ao agente privado as decisões de se prover um insumo básico às atividades econômicas e essencial à qualidade de vida da população, assim como negligencia a sinergia entre esse setor e a implementação de políticas públicas de desenvolvimento, ações que se mostraram pouco efetivas nos anos 2000, em termos de garantia da confiabilidade do sistema elétrico.

\section{CONCLUSÕES}

O setor elétrico brasileiro, de matriz majoritariamente hídrica, foi constituído em bases estatais com o intuito de prover o insumo energia elétrica ao processo de industrialização, a partir da década de 1930.

As reformas setoriais dos anos de 1990, após a crise fiscal e financeira do Estado, foram implementadas em consonância com as transformações do capitalismo global, que estabeleceram a financeirização como padrão sistêmico de riqueza, e tornaram o setor elétrico locus de acumulação de capital. A privatização das empresas e as parcerias público-privadas possibilitaram a mudança de empresas nacionais e estrangeiras, que se diversificaram como geradoras de energia elétrica. Destacam-se 
aqueles setores que estruturam o capitalismo brasileiro e vinculam o setor elétrico à posição do país na divisão internacional do trabalho como produtor de commodities, conforme configuração setorial, marcada pela participação de multinacionais do setor elétrico, grupos de mineração e siderurgia, construção civil e empresas de atividades do serviço financeiro.

No que se refere à ação das empresas estatais, o que se evidencia é que ainda que o marco regulatório de 2004 as tenha retirado do Programa Nacional de Desestatização de 1990 e permitido a retomada de seus investimentos, com destaque para a holding Eletrobrás, a forma de atuação predominante é a parceria público-privada, em um arcabouço institucional de uma empresa privada - a SPE, de maneira que a lógica privada se impõe sobre a lógica pública. Ainda assim, o seu caráter estatal permite a articulação da empresa às políticas de Estado, conforme se verifica com respeito ao PAC.

A nova rodada de neoliberalização inaugurada pelo Governo Temer sinaliza para a retomada das privatizações, com destaque para a empresa estatal Eletrobrás, o que tende a aprofundar o processo de desnacionalização setorial, dado o interesse de multinacionais, com destaque para empresas chinesas, e maior controle externo sobre macrodecisões de desenvolvimento. A análise, portanto, confere ao setor elétrico status de objeto fecundo para se compreender as relações entre o público e o privado no Brasil, Estado e mercado em contexto de neoliberalização, bem como seu vínculo com o padrão de acumulação e inserção internacional em curso.

\section{BIBLIOGRAFIA}

Amaral Filho, J. B. (2007). A Reforma do setor elétrico brasileiro e a questão da modicidade tarifária. Tese de Doutorado. Universidade Federal de Campinas, Campinas, 232p.

Braga, J. C. (1997). Financeirização global: o novo padrão sistêmico de riqueza do capitalismo contemporâneo (p. 195-242). Em: Fiori, José Luis (Ed.). Poder e dinheiro. Petrópolis: Vozes, $411 \mathrm{p}$.

Brandão, C. (2017). Crise e rodadas de neoliberalização: impactos nos espaços metropolitanos e no mundo do trabalho no Brasil. Cad. Metrop., São Paulo, vol. 19, n. ${ }^{3}$ 38, p. 45-69.

Brenner, N.; Peck, J. e Theodore, N. (2012). Após a neoliberalização? Em: Cadernos Metrópole, Estados Unidos, vol. 14, n. ${ }^{\circ}$ 27, p. 15-39.

Buratini, R. (2004). Estado, capitais privados e concorrência no setor elétrico brasileiro: da constituição do modelo estatal à crise do modelo competitivo. Tese de Doutoramento, Universidade Estadual de Campinas, 237p.

Cardoso, J. G. R.; Carvalho, P. S. L.; Fonseca, P. S. M.; Silva, M. M. e Rocio, M. A. R. (2011). A Indústria do alumínio: estrutura e tendências. BNDES Setorial, n. ${ }^{\circ}$ 33. Rio de Janeiro, p. 43-88. 
Espósito, A. S. (2012). O setor elétrico brasileiro e o BNDES: reflexões sobre o financiamento aos investimentos e perspectivas. Em: Souza, Filipe Lage de (Org.). BNDES 60 ANOS. Rio de Janeiro: Perspectivas Setoriais, $\overline{231}$.

Fernández, V. R. (2016). Desde el laboratorio neo-desarrollista a la resurgencia neoliberal: una revisión creative del 'doble movimiento' polanyano en América Latina. Em: Revista Estado y Políticas Públicas, n. ${ }^{\circ}$, p. 21-47.

Harvey, D. (1982). The limits to Capital. Oxford: Basil Blackwell Publisher, 512p.

Hirschman, A. (1958). Estratégia do Desenvolvimento Econômico. Rio de Janeiro: Editora Fundo de Cultura S.A., 488p.

Jardim, M. A. C. (2009). Entre a solidariedade e o risco: sindicatos e fundos de pensão em tempos de governo Lula. São Paulo: Annablume Editora, 423p.

Miranda, J. C. e Tavares, M. C. (1999). Brasil: estratégias de conglomeração (327-350). Em: Fiori, José Luis (Org.). Estados e Moedas no Desenvolvimento do Brasil. 3 ed. Petrópolis: Vozes, 492p.

Oliveira, F. O. (1988). Surgimento do Antivalor. Em: Novos Estudos, n. ํ. 2, 28p.

Paulani, L. (2013). Acumulação sistêmica, poupança externa e rentismo: observações sobre o caso brasileiro. Em: Estudos Avançados, vol. 27, n. ${ }^{\circ}$ 77, São Paulo. p. 237-264.

Paulani, L. (2016). Acumulação e Rentismo: resgatando a teoria da renda de Marx para pensar o capitalismo contemporâneo. Em: Revista de Economia Política, vol. 36, n. ${ }^{\circ}$ 3, p. 514-535.

Peck, J. (2010). Constructions of Neoliberal Reason. Oxford: Oxford University Press, 324p.

Pêgo, B. e Campos Neto, C. A. S. (2008). O PAC e o setor elétrico: desafios para o abastecimento do mercado brasileiro (2007-2010). IPEA, 32p.

Rosa, L. P. (2001). A crise energética: uma reputação empírica do modelo econômico neoliberal. Em: Lessa, Carlos (Org.). O Brasil à luz do apagão. Rio de Janeiro: Palavra E Imagem, 320p.

Sauer, I. L. (2002). Energia elétrica no Brasil contemporâneo: a reestruturação do setor elétrico, questões e alternativas. Em: Antônio Murgel Branco (Org.). Política energética e crise de desenvolvimento: a antevisão de Catullo Branco. São Paulo: Paz e Terra, 284p.

Tavares, M. C. (1978). Da substituição de importações ao capitalismo financeiro. Rio de Janeiro: Zahar Editores, 7 edição, 263p.

Theodore, N.; Peck, J. e Brenner, N. (2009). Urbanismo neoliberal: la ciudad y el imperio de los mercados, $12 \mathrm{p}$.

Vieira, J. (2007). Antivalor: um estudo da energia elétrica: construída como antimercadoria e reformada pelo mercado nos anos 1990. São Paulo: Paz e Terra, 312p.

Werner, D. (2016). Estado, capitais privados e territórios no processo de reconfiguração do setor elétrico brasileiro pós-1990. Tese de Doutoramento, IPPUR/UFRJ, Brasil, 434p.

\section{OUTRAS REFERÊNCIAS}

Aneel —Agência Nacional de Energia Elétrica - (2019). Participação Acionária das Empresas de Geração de Energia Elétrica. 
Brasil (2014). Estudo da Eficiência Energética. Nota Técnica DEA 10/14.

Camara dos Deputados (2018). Projeto de Lei 9.463, de 2018. Dispõe sobre desestatização da Eletrobrás.

CPFL Energia (2016). Estrutura Societária.

EBC —Empresa Brasileira de Comunicações— (2016). Governo assina contratos de concessão de 29 usinas hidrelétricas.

EBC —Empresa Brasileira de Comunicações — (2018). Alexandre de Moraes libera MP que permite privatização da Eletrobrás.

EPE —Empresa de Pesquisa Energética- (2018). Consumo de Energia no Brasil. Análises Setoriais. Nota Técnica DEA 10/14.

O Estado de São Paulo (2017). Empresa chinesa compra fatia da Cemig na Hidrelétrica Santo Antônio.

FNU —Federação Nacional dos Urbanitários - (2018). Temer quer entregar Eletrobrás a fundos americanos e europeus.

Presidência da República (2004). Lei 10.847, de 15 de março de 2004. Autoriza a criação da Empresa de Pesquisa Energética e dá outras providências. Casa Civil, Brasil.

Presidência da República (2004). Lei 10.848, de 15 de março de 2004. Dispõe sobre a comercialização de energia elétrica e dá outras providências. Casa Civil, Brasil.

Presidência da República (2004). Lei 11.079, de 30 de dezembro de 2004. Institui normas gerais para licitação e contratação de parcerias público-privadas da administração pública. Casa Civil, Brasil.

Presidência da República (2013). Lei 12.783, de 11 de janeiro de 2013. Dispõe sobre concessões do setor elétrico e dá outras providências. Casa Civil, Brasil.

MDIC —-Ministério do Desenvolvimento Indústria e Comércio— (2007). Apresentação. Programa de Aceleração do Crescimento, 55p.

MME —Ministério de Minas e Energia - (2017). Nota Técnica. No 5/2017/AEREG/SE. Processo $N^{\circ} 48000.001405 / 2016-67$.

Murakawa, F. (2018). Senador protocola pedido de CPI da privatização.

Nunes, F. (2017). Presidente da Eletrobras chama funcionários de vagabundos.

Repórter Brasil (2016). Quem são os chineses de olho na Amazônia. 